\title{
Effects of sport therapy on psychosocial outcomes for forensic patients
}

\section{A systematic review of evidence in mentally ill patients}

\author{
Vanessa Reimer, Thomas Ross, and Martina Kanning \\ Fach Sportwissenschaft, Universität Konstanz, Konstanz, Germany
}

\begin{abstract}
Physical activity has gained importance in psychiatric and psychosomatic treatment schemes, but there is little knowledge on the use of physical activity for forensic rehabilitation, including psychosocial outcomes. A systematic review of the literature on PubMed and Livivo found only one study that specifically addressed the effects of physical activity in forensic patients. Twenty-three studies reported on physical activity in the context of non-forensic patients suffering from mental illnesses similar to those commonly diagnosed in forensic patients. We summarize the effects of physical activity with respect to therapeutic objectives suggested by German sport therapists working with forensic patients. In forensic patients or patients suffering from mental illness typical of forensic patients, physical activity promotes social skills (4 studies), self-image, body experience, and personality growth (9 studies). Physical activity also helps to activate patients (12 studies), while reducing their tension and anger (1 study). Yet, there is a significant lack of specific scientific evidence as to whether sport therapy for forensic patients is effective in terms of the therapeutic objectives of this patient group. Future research must focus on longitudinal dose-effect outcome studies on forensic patients and should also concentrate on studies in the area of psychosis, personality disorders and addiction in relation to forensic sport therapeutic objectives.
\end{abstract}

Keywords: Physical activity, mental illness, personality, social skills, psychiatry

\section{Introduction}

Physical activity (PA) in the frame of sport therapy in psychiatry and psychosomatics is becoming increasingly important, as positive effects have been reported for mental illnesses and stress [1]. Sport therapy is an exercise therapy intervention that particularly incorporates elements of educational, psychological, and socio-therapeutic practices [2]. Meta-analytic studies show positive effects of PA in patients suffering from psychiatric disorders relevant to the field of general psychiatry, including symptoms of schizophrenia [3-7], alcohol addiction [8], substance use disorders [9], and depression or depressive symptoms [3, 6, 10-12]. Many of these disorders or psychiatric symptoms are also common in forensic psychiatric patients. In the context of forensic psychiatric treatment, PA seems to be associated with positive effects pertaining to social risk and other health related behaviors [13].

There is plenty of general evidence on the effects of PA on mental illness, but little on psychosocial outcomes, or the treatment objectives of sports therapy. Yet, there is a lack of scientific evidence for its effectiveness in the overall structure of forensic psychiatric treatment, especially as far as psychosocial measures of change are concerned. Forensic psychiatric patients tend to be multi-morbid and to suffer from a multitude of symptoms pertaining to a wide range of mental illnesses as well as socio-psychological deficits associated with crime [13]. Mental disorders associated with offending and recidivism into criminal behavior include personality disorders, especially of the cluster B type (antisocial, borderline and narcissistic disorders, less frequently histrionic personality disorders), schizophrenic and other schizophreniform psychotic disorders. Psychosocial deficits typical of many forensic patients include little or no insight into their mental illnesses and related problems; antisocial attitudes and dysfunctional values and beliefs (e.g. my violence is not my fault, the others are out to get me, I am just defending myself); impulsivity, hostility, anger and poor social problem-solving skills. Apart from the fact that many forensic professionals believe in the positive effects of psychotherapeutic treatments and other specialized treatment programs for offenders on some psychosocial problem areas of patients, especially impulsivity, hostility, anger and poor social problem-solving skills, little is known about the psychosocial effects of PA in forensic patients. 
The purpose of this systematic review of current evidence is to summarize and structure the evidence available on psychosocial effects of PA in patients with mental disorders relevant in the field of forensic psychiatry (e.g. schizophrenia, personality disorders, intellectual disabilities, and addiction). To structure any psychosocial benefits or effects, we have used the sports therapeutic treatment goals as described by Ross et al. [14] as the main criteria for psychosocial outcomes. These are (the development of) social skills, coping with conflict and frustration, the stabilization of personality, physical and psychological activation, correction of self-image, and changes in body experience.

\section{Treatment effects for patients in forensic psychiatry}

Forensic psychiatric treatment includes individual and group psychotherapy, as well as a number of complementary therapies, such as art, work, music, or PA. Evidence on the efficacy of complementary therapies is scarce, but there is a considerable body of research on psychotherapeutic approaches to the treatment of forensic patients [15-17]. Yet, all therapeutic approaches have commonalities, as described in the literature on general psychotherapy. The five major mechanisms of therapeutic change are: therapeutic alliance, resource activation, problem actualization, motivation, and coping $[18,19]$. PA as a building block of a general treatment strategy for mentally ill offenders is expected to produce controllable effects on rule-compliant and pro-social behavior (team spirit, fairness), aggression management, frustration tolerance, body perception and positive body experience, self-efficacy, self-esteem, selfcalming, and reconciliation [20]. While anxiety, tension and depressive moods can be reduced [20], there is little research on whether these treatment objectives can be attained with forensic patients.

\section{Sport therapeutic objectives for forensic patients}

Based on 55 expert interviews with sport therapists, specific sport therapeutic objectives for patients treated in German forensic psychiatric units were identified [14]. The most important sport therapeutic treatment objectives for the treatment of patients under mental health detention orders according to section 63 of the German Penal Code $^{1}$ [21] (mentally ill forensic patients) were: the development of social skills, coping with conflict and frustration, the stabilization of personality, and physical and psychological activation. For substance-dependent patients treated according to section 64 of the German Penal Code ${ }^{2}$ [22], two treatment objectives were identical, and two others emerged: development of social skills, coping with conflict and frustration, correction of self-image, and changes in body experience.

According to the sports therapists interviewed [14], the objectives of PA evolved as a result of offering structured PA to hundreds of forensic patients. Whether or not the developmental targets set forth by the therapists actually match the scientific evidence on the efficacy of PA in general, remains unclear. The same applies to the evidence on the efficacy of PA to change psychiatric symptoms and dangerous behaviors in forensic psychiatric patients. This review presents evidence on sports therapy as regards the six sport therapeutic objectives in forensic psychiatric patients.

\section{Methods}

A comprehensive literature search following the PRISMA guidelines was carried out in the databases PubMed and Livivo. The inclusion criteria were: papers (1) published in English that (2) covered mentally ill persons, for whom interventions connecting to the psychosocial performance indicators laid out by forensic sport therapists were carried out. Excluded were articles not pertaining to the mental illness found in forensic psychiatry or those that did not relate to forensic sport therapeutic objectives.

To systematically evaluate the grade of evidence, we used the Grading of Recommendations Assessment, Development, and Evaluation (GRADE) framework [23]. Because this review is about effects regarding any kind of PA on different sport therapeutic objectives, randomized controlled studies or reviews were labeled first-grade evidence (1), prospective and longitudinal studies were labeled second-grade evidence (2), and cross-sectional studies were labeled third-grade evidence (3). The literature search was completed in March 2021 and the following search terms were applied:

\footnotetext{
${ }^{1}$ German Criminal Code, Section 63: Placement in psychiatric hospital. If a person has committed an unlawful act in a state of criminal irresponsibility or in a state of diminished responsibility, the court orders the person's placement in a psychiatric hospital if the overall evaluation of the offender and of the offense reveals that, due to the offender's condition, he or she represents a danger to the general public. ${ }^{2}$ German Criminal Code, Section 64: Placement in addiction treatment facility. If a person has an addiction to alcoholic drinks or other intoxicating substances and is convicted of an unlawful act which was committed in a state of intoxication or as a result of an addiction, court is, as a rule, to order placement in an addiction treatment facility if there is a danger that said person will in future commit serious unlawful acts as a consequence of this proclivity.
} 


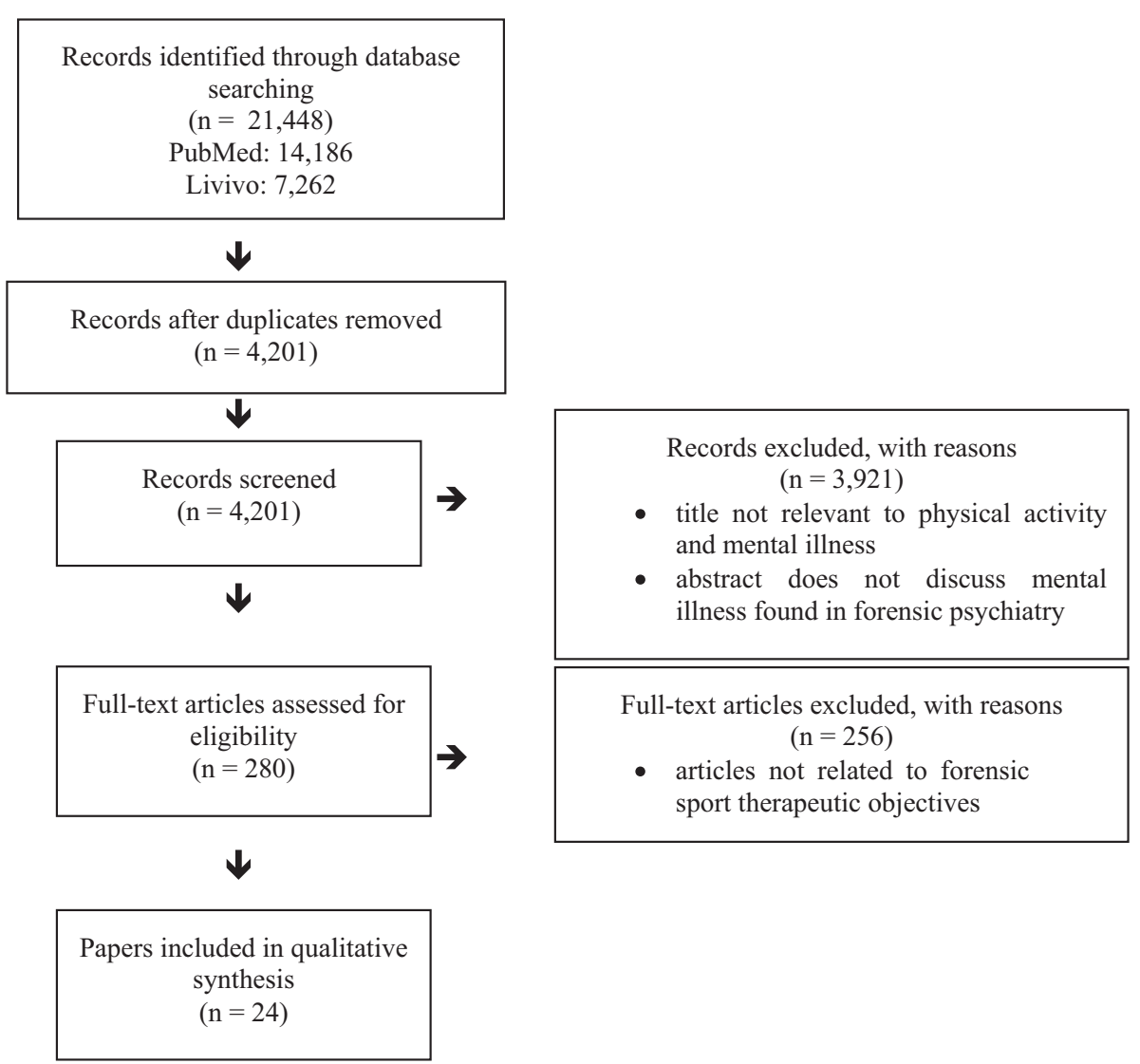

Figure 1. Study selection for systematic review of current evidence.

- physical activity OR physical exercise OR sport therapy

- AND forensic psychiatry OR forensic patients OR offenders

- AND mental illness OR schizophrenia OR psychosis OR personality disorder OR addiction OR depression OR anxiety

- AND personality OR social skills OR empathy OR activation OR motivation OR self-image OR conflicts OR frustrations

\section{Results}

The analysis of the search terms resulted in 508 hits. After excluding inappropriate articles, only one study on forensic patients remained. Therefore, the forensic search terms (forensic psychiatry OR forensic patients OR offenders) were omitted in the second search. The second search resulted in a total of 21,448 hits. As a result, 24 publications were deemed thematically appropriate to represent the six forensic sport therapeutic objectives. These are described in more detail. Figure 1 contains a flowchart of the search routine. A summary of the classification of the grade of evidence is listed in Table 1. Eleven of twenty-four studies were rated grade 1 , i.e. more than $50 \%$ of the studies were crosssectional.

\section{Social skills}

Four studies reported positive effects of PA on social skills, social functions, and empathy of patients suffering from mental disorders (other than schizophrenia; $\mathrm{n}=2$ ) or schizophrenia $(\mathrm{n}=2)$.

Social skills are cognitive, emotional, and motor behaviors that may lead to a long-term favorable relationship between people [24]. PA, walking programs, and an accumulation of moderate-intensity activity can counteract social withdrawal in patients with serious mental illness [25]. The empathic ability is significantly better in chronically mentally ill patients receiving long-term (up to six months) than short-term (up to three months) group-based PA [26]. Soccer training sessions, which occur regularly and typically last for at least three months, improve the social skills of schizophrenic patients [27, 28]. In one study, the intervention group was trained twice a week for 100 to 120 minutes over the course of 12 weeks, whereas the control group did not receive regular training during this period [27]. The training units were subdivided into six subphases, including a "social phase" to promote "social interaction and competence" and a "feedback phase" to promote participants' "self-worth and adaptive selfbeliefs" [27]. In addition to the enhancement of the physical parameters, there were improvements to the mental 


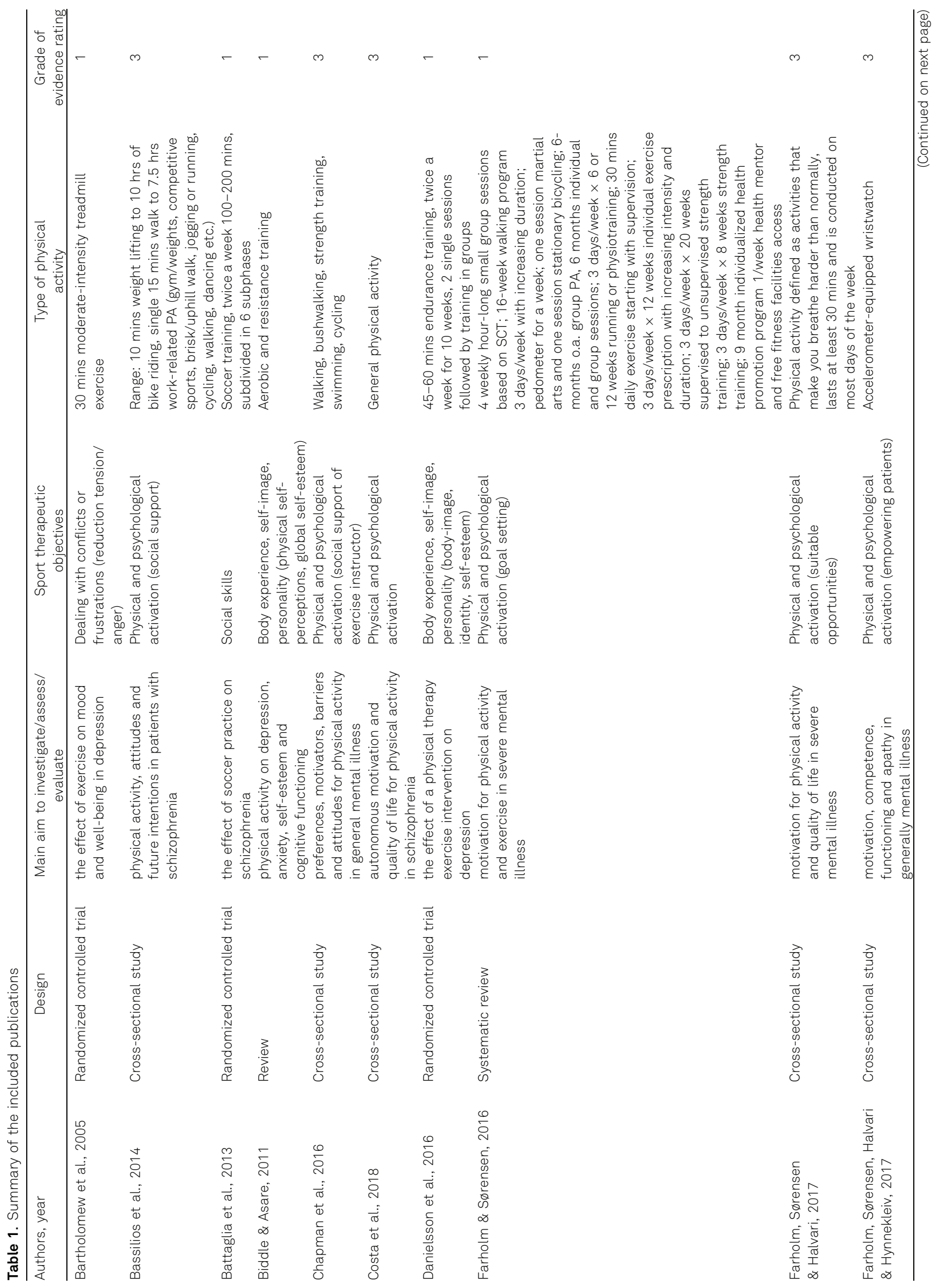




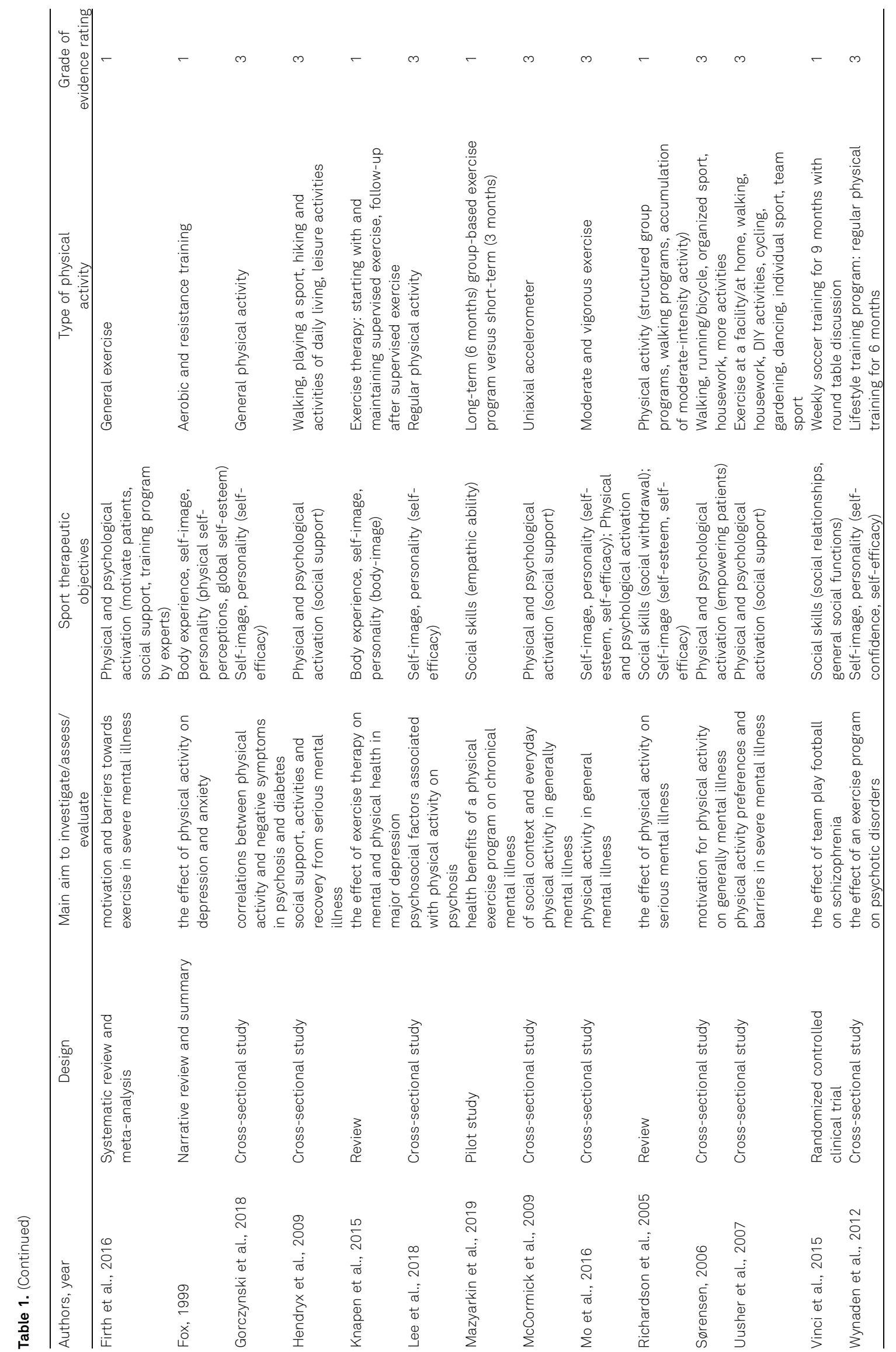


components of the intervention group, such as "role limitations caused by emotional problems, social functioning, vitality" and "mental health" [27]. In the other study, weekly soccer training with only male schizophrenic subjects was conducted over the course of nine months, which consisted of both training and a game as well as a weekly round table discussion with a psychiatric operator [28]. The control group and the intervention group both continued to engage in their activities, such as carpentry and other work activities [28]. Compared to the control group, the intervention group showed significant psychopathological improvements, a reduction of negative symptoms, improvement of overall physical and mental health, enhanced self-awareness, and an improvement of social relationships and general social functions [28].

\section{Body experience, self-image and stabilization of personality}

Nine articles investigating the effects of PA on body experience, self-image, and personality in patients suffering from mental disorder $(\mathrm{n}=2)$, psychosis $(\mathrm{n}=3)$, or depression $(n=4)$.

Generally, for serious mental illness, PA promotes selfesteem and self-efficacy [25, 29], meaning structured group programs (walking programs) and a lifestyle modification (30 minutes of moderate-intensity activity per day), with at least three 20- to 60-minute exercise sessions per week [25]. In patients with psychosis, PA may also have significant effects on self-efficacy [30,31], depending on the frequency, duration and intensity of physical activity [30]. This has also been demonstrated in a lifestyle-training program conducted within the State Forensic Mental Health Service in Australia [32], where regular physical training was offered over the course of six months. The aforementioned positive effects included symptom management, an increase in overall fitness, and improvements to self-confidence and self-esteem [32]. This was the only study directly related to forensic psychiatric outcomes [32]. Obviously, there is a significant lack of studies linking the objectives and effects of PA to forensic psychiatric patients.

Aerobic and resistance training can improve physical self-perception and global self-esteem in individuals suffering from depression or anxiety [33, 34]. PA in people with depression improves body image, strategies for coping with stress, quality of life, and independence in daily activities in older adults [10,35]. The intervention lasted 10 weeks and included 45-60 minutes of endurance training twice a week [35]. The first two units were single sessions, followed by training in small groups of eight subjects each. Data was collected through interviews in which the patients' experiences were divided into four categories. The first category, "struggling toward your healthy self", pertains to a patient's sense of empowerment, and may help motivate patients to live a more actively, to experience pride and joy through PA, to get a feeling of being physically and psychologically sound, and to regain a healthy self-image and identity, and participate in (social) life. The second category, "challenging the resistance", pertains to self-satisfaction after PA, as well as a boost of self-esteem. The third category, "feeling more alive but not euphoric", refers to the patients being more vigilant, gentle, mobile, and energetic after exercise. The patients reported good feelings as a result of experiencing their own bodies in motion. In addition, exercise raised their general mood. However, some patients reported that the movement intervention did not bring about the hoped-for euphoric feelings. The last category, "needing someone to be there for you" emphasizes the importance of the physical therapist as a source of support and motivation, helping the participants to overcome motivational lapses and keep up the training until the end.

\section{Physical and psychological activation}

12 publications were found that show the positive effects of PA on the activation of patients suffering from mental disorders $(n=9)$ or, specifically, schizophrenia $(n=3)$.

In patients suffering from mental disorders, lack of motivation, lack of self-determination, fatigue, illness etc. are associated with significantly lower levels of PA $[29,36,37]$. In order to help patients with severe mental illnesses to engage in PA, the sessions should match the patients' abilities and (psychosocial) needs [38]. Measures that may help are structured training in a facility [37], social support [37, 39-42], the support of an exercise instructor $[37,39]$, the promotion of intrinsic and extrinsic motivation (empowering patients to control their training independently) [36, 43, 44], motivational interviewing, and goal setting [45]. In addition to pursuing physiological goals, it is also recommended to make use of exercise programs that provide psychological support to patients [40] and promote interaction with others [46].

\section{Coping with conflict and frustration}

One study investigating the effect of PA on the ability to deal with tension and anger was identified among patients with depression.

In patients with major depressive disorders, a 30-minute moderate-intensity treadmill exercise $(60-70 \%$ of maximum heart rate), paired with mood recording five minutes before the intervention, five minutes after, 30 minutes after, and 60 minutes after, was found to reduce psychological stress, depression, confusion, fatigue, tension, and anger [47]. 


\section{Discussion}

Six treatment objectives [14] served to structure and summarize the effects of PA on patients undergoing forensic psychiatric treatment. To the best of our knowledge, this is the first review that examines therapeutic objectives as defined by sport therapists active in forensic psychiatric facilities. PA is meaningfully associated with the psychosocial effects of patients with severe mental illness, especially if PA is administered in a group format (group exercise). It is possible that individual, tailored sports programs may be effective for some patients, but little is known about the specific effects of individual compared to team sports programs, probably because individual training is much less commonly used in forensic practice than team or group training (individual training requires one therapist for one patient, whereas team programs can be implemented much more cost-effectively). In addition, group training programs contain a much stronger psychosocial skills component than individual ones. There is a wealth of studies linking PA to the promotion and development of social skills and the physical and psychological activation of the patient. There is some evidence that structured PA may be associated with correction of the self-image, change in body experience, and stabilization of personality, but additional studies are required. Surprisingly, no literature was found on learning to deal appropriately with conflicts or frustrations. From a clinical point of view, it is obvious that coping with conflict and frustration should be a cornerstone of all psychiatric treatment efforts, since conflict resolution and reducing psychological tension (between patients and between patients and staff) is a daily routine within the wards. Clearly, this does not apply only to forensic psychiatric patients, but to all kinds of psychiatric patients.

Coping with conflict and frustration reflects a set of behaviors that can be conceived of as part of other treatment targets, i.e. the promotion of social skills (learning to deal with conflict and frustration are both social skills). Thus, conflict and frustration may be a subgroup within a larger set of behaviors referred to as social skills, which is why using these designations as the principal search terms for a literature review may not be sensitive. Furthermore, only one study involving forensic patients was found [32]. Apparently, German forensic sport therapists focus more on the psychological outcomes of sport therapeutic activity than the physical outcomes. Based on this review, it seems that most treatment targets expressed by these professionals are backed by scientific evidence pertaining to the sport therapeutic treatment of psychosomatic and psychiatric patients in general, but not for forensic patients. Patients in general psychiatric treatment do not differ much from forensic patients in terms of the aforementioned (specific) mental disorders they suffer from. Therefore, PA could be effective for forensic psychiatric patients, too. To test this assumption, specific research on psychosocial performance of forensic psychiatric patients as a result of sport therapeutic intervention is needed.

\section{Limitations}

Cross-sectional studies showed that mentally ill patients may be highly motivated to participate in physical activities and that positive effects on various parameters of mental illness are likely as a result of PA. The problem is that cross-sectional studies do not show causal relationships between PA and mental outcomes. Yet, our point of view is that the results of the cross-sectional studies may be a good starting point for planning RCT-studies. Crosssectional studies provide assumptions about possible associations between PA and sport therapeutic objectives in the field of mental health. These assumptions should be used to plan and conduct other types of studies more suitable to elucidate causal relationships between PA and mental outcomes in forensic patients. For this reason, the above-mentioned findings do not all refer to RCTs, but also to cross-sectional studies.

\section{Conclusion}

Sport therapeutic treatment goals for forensic patients are mainly directed at improving psychosocial performance. Yet, there is little scientific evidence suggesting that forensic patients benefit from PA in terms of acquiring psychosocial competencies. Based on relevant findings on (general) psychiatric patients suffering from the same mental disorders as forensic patients do, one may hypothesize that PA will be effective for forensic psychiatric patients, too. But currently, the evidence is missing and should be provided; otherwise, PA with forensic patients will continue to stand on shaky ground. Longitudinal dose-effect outcome studies on forensic patients, controlling for psychiatric diagnoses and index offences, should be designed and carried out.

\section{References}

1. Lukowski T. Bewegungstherapie als dritte Säule der Behandlung. DNP - Der Neurologe \& Psychiater. [Exercise therapy as the third pillar of treatment. DNP - The neurologist \& psychiatrist]. 2018;19(4):44-9. https://doi.org/10.1007/s15202018-1882-0

2. DVGS. Deutscher Verband für Gesundheitssport und Sporttherapie e.V. Definition der Sport- und Bewegungstherapie. [German Association for Health Sport and Sports Therapy e.V. Definition of Sports and Exercise Therapy]. Retrieved from: https://dvgs.de/de/sport-bewegungstherapie/definition.html (16.03.2021) 
3. Rosenbaum S, Tiedemann A, Sherrington C, Curtis J, Ward PB. Physical activity interventions for people with mental illness: A systematic review and meta-analysis. The Journal of Clinical Psychiatry. 2014;75(9):964-74. https://doi.org/ 10.1016/j.jsams.2014.11.161

4. Soundy A, Freeman P, Stubbs B, Pobst M, Coffee P, Vancampfort D. The transcending benefits of physical activity for individuals with schizophrenia: a systematic review and meta-ethnography. Psychiatry Research. 2014;220(1-2): 11-9. https://doi.org/10.1016/j.psychres.2014.07.083

5. Vancampfort D, Rosenbaum S, Probst M, Soundy A, Mitchell AJ, De Hert M, et al. Promotion of cardiorespiratory fitness in schizophrenia: a clinical overview and meta-analysis. Acta Psychiatrica Scandinavica. 2015;132(2):131-43. https://doi. org/10.1111/acps.12407

6. Vancampfort D, Rosenbaum S, Schuch F, Ward PB, Richards $J$, Mugisha J, et al. Cardiorespiratory Fitness in severe mental illness: a systematic review and meta-analysis. Sports Medicine (Auckland, N.Z.). 2017;47(2):343-52. https://doi. org/10.1007/s40279-016-0574-1

7. Vancampfort D, Rosenbaum S, Ward PB, Stubbs B. Exercise improves cardiorespiratory fitness in people with schizophrenia: A systematic review and meta-analysis. Schizophrenia Research. 2015;169(1-3):453-57. https://doi.org/10.1016/j. schres.2015.09.029

8. Hallgren M, Vancampfort D, Giesen ES, Lundin A, Stubbs B. Exercise as treatment for alcohol use disorders: systematic review and meta-analysis. British Journal of Sports Medicine. 2017;51(14):1058-64. https://doi.org/10.1136/bjsports-2016096814

9. Wang D, Wang Y, Wang Y, Li R, Zhou C. Impact of physical exercise on substance use disorders: a meta-analysis. PLoS One. 2014;9(10):e110728. https://doi.org/10.1371/journal.pone. 0110728

10. Knapen J, Vancampfort D, Moriën Y, Marchal Y. Exercise therapy improves both mental and physical health in patients with major depression. Disability and Rehabilitation. 2015;37 (16):1490-5. https://doi.org/10.3109/09638288.2014.972579

11. Kvam S, Kleppe CL, Nordhus ICH, Hovland A. Exercise as a treatment for depression: A meta-analysis. Journal of Affective Disorders. 2016;202:67-86. https://doi.org/10.1016/ j.jad.2016.03.063

12. Rimer J, Dwan K, Lawlor DA, Greig CA, McMurdo M, Morley W, et al. Exercise for depression. The Cochrane Database of Systematic Reviews. 2012;7(7):CD004366. https://doi.org/ 10.1002/14651858.CD004366.pub5

13. Schmid O, Abele L, Wichmann P, Kluttig T, Hoffmann K, Mess F. Sporttherapeutische Ansätze in der forensischen Psychiatrie. [Sports therapeutic approaches in forensic psychiatry]. Forensische Psychiatrie und Psychotherapie. 2016;23(3):315-35.

14. Ross T, Reder S, Querengässer J, Mess F, Schmid O. Sporttherapie in der forensischen Psychiatrie und Psychotherapie - eine Standortbestimmung. [Sports therapy in the forensic psychiatry and psychotherapy - an assessment of the situation]. Forensische Psychiatrie und Psychotherapie. 2016;23(1):37-65.

15. Konrad N, Huchzermeier C, Rasch W. (Eds.). Forensische Psychiatrie und Psychotherapie. Rechtsgrundlagen, Begutachtung und Praxis. 5. Aufl. [Forensic Psychiatry and Psychotherapy. Legal basis, assessment and practice. 5th ed]. Stuttgart: Kohlhammer; 2019.

16. Kröber H-L, Leygraf N, Dölling D, Sass H. (Eds.). Handbuch der Forensischen Psychiatrie Band 3 (Psychiatrische Kriminalprognose und Kriminaltherapie). [Manual of the forensic psychiatry, volume 3 (psychiatric criminal prognosis and criminal therapy)]. Heidelberg: Steinkopff; 2006.
17. Müller JL, Nedopil N. (Eds.). Forensische Psychiatrie. Klinik, Begutachtung und Behandlung zwischen Psychiatrie und Recht. 5. Aufl. [Forensic psychiatry. Clinic, assessment and treatment between psychiatry and law. 5. ed]. Stuttgart: Thieme; 2017.

18. Grawe K. Psychologische Therapie (2. Aufl.). [Psychological Therapy] (2nd ed.). Göttingen: Hogrefe; 2000.

19. Grawe K. Neuropsychotherapie. [Neuropsychotherapy]. Göttingen: Hogrefe; 2004.

20. Schmidt-Quernheim F. Behandlung im Maßregelvollzug gemäß § 63 StGB. In Schmidt-Quernheim F, Hax-Schoppenhorst T (Eds.). Praxisbuch forensische Psychiatrie. Behandlung und ambulante Nachsorge im Maßregelvollzug. 3. vollständig überarbeitete und erweiterte Auflage. [Treatment book forensic psychiatry. Treatment and outpatient aftercare in the execution of disciplinary measures. 3. complete revised and extended edition]. 262-266. Bern: Hogrefe; 2018.

21. Andrews DA, Zinger I, Hoge RD, Bonta J, Gendreau P, Cullen FT. Does correctional treatment work? A clinically relevant and psychologically informed meta-analysis. Criminology. 1990;28(3):369-404. https://doi.org/10.1111/j.1745-9125. 1990.tb01330.x

22. Andrews DA, Bonta J, Wormith JS. The Risk-NeedResponsivity (RNR) model. Does adding the Good Lives Model contribute to effective crime prevention? Criminal Justice and Behavior 2011;38(7):735-55. https://doi.org/10.1177/ 0093854811406356

23. Guyatt GH, Oxman AD, Schünemann HJ, Tugwell P, Knottnerus A. GRADE guidelines: A new series of articles in the Journal of Clinical Epidemiology. Journal of Clinical Epidemiology. 2011; 64(4):380-2. https://doi.org/10.1016/j.jclinepi.2010.09.011

24. Hinsch R, Pfingsten U. Gruppentraining sozialer Kompetenzen GSK. 5., vollständig überarbeitete Auflage. [Group training of social competences GSK. 5., completely revised edition]. Weinheim, Basel: Beltz; 2007.

25. Richardson CR, Faulkner G, McDevitt J, Skrinar GS, Hutchinson DS, Piette JD. Integrating physical activity into mental health services for persons with serious mental illness. Psychiatric Services (Washington, D.C.). 2005;56(3):324-31. https://doi.org/10.1176/appi.ps.56.3.324

26. Mazyarkin Z, Peleg T, Golani I, Sharony L, Kremer I, Shamir A. Health benefits of a physical exercise program for inpatients with mental health: a pilot study. Journal of Psychiatric Research. 2019;113:10-6. https://doi.org/10.1016/j.jpsychires. 2019.03.002

27. Battaglia G, Alesi M, Inguglia M, Roccella M, Caramazza G, Bellafiore $M$, et al. Soccer practice as an add-on treatment in the management of individuals with a diagnosis of schizophrenia. Neuropsychiatric Disease and Treatment. 2013;9:595-603. https://doi.org/10.2147/NDT.S44066

28. Vinci G, Zampaglione G, Grossi F, Balbi A, Mannocci A, Masala D. Randomized controlled clinical trial on the efficacy of team play football on schizophrenic patients: a pilot study. Senses and Sciences. 2015;2(1):24-30. https://doi.org/10.14616/ sands-2015-1-2430

29. Mo PKH, Chong ES, Mak WW, Wong SY, Lau JT. Physical activity in people with mental illness in Hong Kong: application of the health belief model. Journal of Sport \& Exercise Psychology. 2016;38(2):203-8. https://doi.org/10.1123/ jsep.2015-0061

30. Gorczynski P, Vancampfort D, Patel H. Evaluating correlations between physical activity, psychological mediators of physical activity, and negative symptoms in individuals living with psychosis and diabetes. Psychiatric Rehabilitation Journal. 2018;41(2):153-6. https://doi.org/10.1037/ prj0000298 
31. Lee JTM, Law EYL, Lo LLH, Lin J, Lee EHM, Hui CLM, et al. Psychosocial factors associated with physical activity behavior among patients with psychosis. Schizophrenia Research. 2018;195:130-5. https://doi.org/10.1016/j.schres. 2017.09.042

32. Wynaden D, Barr L, Omari O, Fulton A. Evaluation of service users' experiences of participating in an exercise programme at the Western Australian State Forensic Mental Health Services. International Journal of Mental Health Nursing. 2012;21(3):229-35. https://doi.org/10.1111/j.1447-0349.2011. 00787.x

33. Biddle SJ, Asare M. Physical activity and mental health in children and adolescents: a review of reviews. British Journal of Sports Medicine. 2011;45(11):886-95. https://doi.org/ 10.1136/bjsports-2011-090185

34. Fox KR. The influence of physical activity on mental wellbeing. Public Health Nutrition. 1999;2(3A):411-8. https://doi. org/10.1017/S1368980099000567

35. Danielsson L, Kihlbom B, Rosberg S. "Crawling out of the cocoon": patients' experiences of a physical therapy exercise intervention in the treatment of major depression. Physical Therapy. 2016;96(8):1241-50. https://doi.org/10.2522/ptj. 20150076

36. Sørensen M. Motivation for physical activity of psychiatric patients when physical activity was offered as part of treatment. Scandinavian Journal of Medicine \& Science in Sports. 2006;16(6):391-8. https://doi.org/10.1111/j.1600-0838.2005. 00514.X

37. Uusher M, Stanbury L, Cheeseman V, Faulkner G. Physical activity preferences and perceived barriers to activity among persons with severe mental illness in the United Kingdom. Psychiatric Services. 2007;58(3):405-8. https://doi.org/ 10.1176/appi.ps.58.3.405

38. Farholm A, Sørensen M, Halvari H. Motivational factors associated with physical activity and quality of life in people with severe mental illness. Scandinavan Journal of Caring Sciences. 2017;31(4):914-21. https://doi.org/10.1111/scs.12413

39. Chapman JJ, Fraser SJ, Brown WJ, Burton NW. Physical activity preferences, motivators, barriers and attitudes of adults with mental illness. Journal of Mental Health (Abingdon, England). 2016;25(5):448-54. https://doi.org/10.3109/ 09638237.2016 .1167847

40. Firth J, Rosenbaum S, Stubbs B, Gorczynski P, Yung AR, Vancampfort D. Motivating factors and barriers towards exercise in severe mental illness: a systematic review and meta-analysis. Psychological Medicine. 2016;46(14):2869-81. https://doi.org/10.1017/S0033291716001732

41. Hendryx M, Green CA, Perrin NA. Social support, activities, and recovery from serious mental illness: STARS study findings. The Journal of Behavioral Health Services \& Research. 2009; 36(3):320-9. https://doi.org/0.1007/s11414-008-9151-1
42. McCormick BP, Frey GC, Lee CT, Gajic T, Stamatovic-Gajic B, Maksimovic M. A pilot examination of social context and everyday physical activity among adults receiving Community Mental Health Services. Acta Psychiatrica Scandinavica. 2009;119(3):243-7. https://doi.org/10.1111/j.1600-0447.2008. 01331.x

43. Costa R, Bastos T, Probst M, Seabra A, Vilhena E, Corredeira R. Autonomous motivation and quality of life as predictors of physical activity in patients with schizophrenia. International Journal of Psychiatry in Clinical Practice. 2018;22(3):184-90. https://doi.org/10.1080/13651501.2018.1435821

44. Farholm A, Sørensen M, Halvari H, Hynnekleiv T. Associations between physical activity and motivation, competence, functioning, and apathy in inhabitants with mental illness from a rural municipality: a cross-sectional study. BMC Psychiatry. 2017;17(1):359. https://doi.org/10.1186/s12888-017-1528-3

45. Farholm A, Sørensen M. Motivation for physical activity and exercise in severe mental illness: A systematic review of intervention studies. International Journal of Mental Health Nursing. 2016;25(3):194-205. https://doi.org/10.1111/inm. 12214

46. Bassilios B, Judd F, Pattison P. Why don't people diagnosed with schizophrenia spectrum disorders (SSDs) get enough exercise? Australasian Psychiatry: Bulletin of Royal Australian and New Zealand College of Psychiatrists 2014;22(1):71-7. https://doi.org/10.1177/1039856213510575

47. Bartholomew JB, Morrison D, Ciccolo JT. Effects of acute exercise on mood and well-being in patients with major depressive disorder. Medicine and Science in Sports and Exercise. 2005;37(12):2032-7. https://doi.org/10.1249/01. mss.0000178101.78322.dd

\section{History}

Received September 28, 2021

Accepted December 13, 2021

Published online January 21, 2022

\section{Funding}

We would like to thank the Reichenau Centre for Psychiatry for financing the third-party project funding and the library of the University of Konstanz for paying the fees for open access.

\section{Vanessa Reimer}

Fach Sportwissenschaft

Universität Konstanz

Universitätsstraße 10

78464 Konstanz

Germany

vanessa.reimer@uni-konstanz.de 